\title{
INVERSE MULTIPLE CRITERIA SORTING PROBLEM WITH FUZZY PARAMETERS: AN APPLICATION OF BUILDING ENERGY LABELLING IMPROVEMENT
}

\author{
Billur Ecer ${ }^{1, *}$, Mehmet KabAK $^{2}$ (i) And Metin Dagdeviren ${ }^{2,3}$ (]
}

\begin{abstract}
Classification is defined as the problem of assignment of objects to the predefined classes. In general view, classification problems divided into two groups: classification and sorting problems. Sorting problems define the case of existence of ordered classes for objects, while classes are not ordered in classification problems. Besides these two groups of classification problems, Inverse Multiple Criteria Sorting Problem (IMSCP) is also introduced into the literature in recent years. IMSCP deals with finding the possible actions that can change the assignment of objects to classes in order to obtain the desired classification of objects. The main aim in this study is to propose an extension of IMSCP with fuzzy parameters with a proper solution approach. A case study of building energy labelling improvement in an existing building site in Ankara is solved by using parametric fuzzy solution approach of Carlsson and Korhonen. Obtained results of the application presents the possible actions to improve the energy labels of the buildings within the site. Also, solution results show that the proposed model in this study can be used to improve current Building Energy Performance model in Turkey to a new one with efficiency improvement suggestions.
\end{abstract}

Mathematics Subject Classification. 90C10, 90C70, 90C90.

Received May 31, 2021. Accepted February 8, 2022.

\section{INTRODUCTION}

Decision making techniques have largely been used by researchers and practitioners to solve different problems in a wide application area. Some of these areas can be listed as inventory management $[7,26,27]$, production planning [19], supplier selection [3], quality evaluation [1], website ranking [12], site selection [18], business aircraft selection [9], etc. Some applications of decision making require assignment of objects to predefined classes. These kinds of problems are named as classification problems. Classification problems are divided into two groups as classification and sorting problems respectively based on the definition of classes as ordered or not [31]. In sorting problems, classes of objects are defined in a preference order starting from the most preferred to the least like, very good, good, moderate, bad, very bad or high, medium, low. However, in classification problems, classes are generally descriptive and there is no preference order within the classes.

Keywords. Fuzzy optimization, integer programming, inverse multiple criteria sorting problem, energy efficiency.

1 Ankara Yıldırım Beyazıt University, Industrial Engineering Department, 06010 Ankara, Turkey.

2 Gazi University, Industrial Engineering Department, 06570 Ankara, Turkey.

3 Council of Higher Education, Universiteler Mah, No: 10, 06539 Bilkent-Ankara, Turkey.

${ }^{*}$ Corresponding author: becer@ybu.edu.tr

(c) The authors. Published by EDP Sciences, ROADEF, SMAI 2022 
Classification and sorting problems generally have a complex structure that require consideration of several criteria simultaneously. This kind of decision problems with complex structure are generally handled by multiple criteria decision making methods. Moreover, a new perspective introduced on multiple criteria sorting problems is to improve the current classification in order to obtain a desired classification situation. This perspective is named as Inverse Multiple Criteria Sorting Problem (IMSCP) [21].

The main aim of this study is to propose a mathematical formulation and a solution method for the fuzzy extension IMSCP. A classification improvement procedure under the assumptions of existence of several action performing companies and fuzzy uncertain problem parameters with the working possibility at the same time on different actions is formulated and an application of building energy labelling is solved by using the parametric solution approach of Carlsson and Korhonen [6]. Using such a model would be useful to see the best way for improvement of classification results in complex decision situations with uncertainty.

The main contributions of the paper can be listed as follows:

- An extension of IMSCP with fuzzy uncertain parameters is firstly introduced into the literature.

- Fuzzy parametric solution approach [6] is utilized to solve the problem.

- An application of the proposed model on a case study of building energy labelling improvement is presented.

The rest of the paper is organized as follows: The second section consists a literature review related to measuring and improvement of building energy efficiency studies. Then, definitions of IMSCP and Fuzzy Parametric Solution Approach used in this study are presented in the third section. In the fourth section, the proposed model is explained in detail by giving problem assumptions, notations and mathematical formulation. Next, a case study of building energy labelling improvement is presented in the fifth section in order to demonstrate the applicability of the proposed model. In the sixth section, conclusions and managerial implications of the study are given with suggestions for further studies.

\section{Literature REVIEW}

Measuring and improvement of building energy efficiency was commonly modeled as a multiple criteria decision making problem by researchers in recent years. Some of these studies were summarized as follows:

Energy efficiency improvement decisions for buildings in design stage were made by using a multi-objective optimization model which contains decision variables defining the building structure and energy system being used [10]. The aim of the study was to define design parameters that minimize rational deviation from building energy consumption, $\mathrm{CO}_{2}$ gas emission and investment cost objectives. In Wang et al.'s study [28], quantitative energy performance evaluation methods for existing buildings were analyzed. Energy performance evaluation methods were classified into three groups in this study as calculation based, measurement based and hybrid methods. Building energy performance measurement system was used by Kabak et al. [16] in order to determine energy classes of three buildings based on seven criteria, which has interactions and expressed by linguistic variables. Fuzzy Analytic Network Process (ANP) method was used to assess building performances and comparison of results with Analytic Hierarchy Process (AHP) and Technique of Order Preference by Similarity to Ideal Solution (TOPSIS) methods were presented.

Three sections of a building in Wuhan University campus were evaluated based on six criteria [13]. Results obtained by using ANP were interpreted in views of further improvements. Importance degree of efficient criteria for sustainable improvement of energy performances of hotel buildings in China were determined by using Fuzzy ANP [30]. The obtained results from the decision model, which takes interactions among criteria into account, showed the important factors for performance improvement.

Bayata and Temiz [4] developed a Non-dominated Sorting Genetic Algorithm II (NSGA-II) approach for optimization of design parameters of new buildings in order to define the most energy efficient building design. Objective of the model was to minimize building energy consumption, initial investment costs and $\mathrm{CO}_{2}$ emission simultaneously and they obtained Pareto front by using genetic algorithm. A three-objective optimization model to optimize building energy performance in views of energy consumption for cooling, heating and lighting aspects 
for four different climate regions in Iran was proposed [8]. A Multi-Objective Particle Swarm Optimization (MOPSO) based approach was developed to solve the proposed model and good solutions are obtained in very short solution times.

Ignatius et al. [14] indicated that sustainability is one of the most important concerns in construction projects and evaluated green buildings in Malaysia by using a hybrid approach based on Quality Function Deployment (QFD) and Fuzzy ANP. The study also presented a sensitivity analysis on changing weight value in defuzzification of fuzzy results to analyze changes occur according to opinions of different decision makers. A building energy performance evaluation approach based on Additive Ratio ASsessment (ARAS) multiple criteria decision making method was proposed [20]. Seven criteria related to economic, technical and environmental aspects of building energy performance were considered in the study. Obtained results showed energy performance building energy performance is not directly proportional to investment, in other words, additional expenses do not affect building energy performance.

Jeong et al. [15] proposed a revised version against possible problems related to criteria and evaluation measures of Building Energy Consumption Certification (BECC) system, which is used for building energy performance evaluation of existing buildings in South Korea. Energy performance classification of 504 buildings was improved by using the proposed system and $K$-means clustering method. Stepwise Weight Assessment Ratio Analysis (SWARA), Weighted Additive Sum Product Assessment (WASPAS) and Building Energy Simulation (BES) have been integrated for selection of Heating, Ventilation and Air Conditioning (HVAC) system for an industrial building [2]. With these integrated methods, eleven HVAC systems were evaluated in ergonomic, environmental, reliability, technical and economic aspects.

The weighted sum method was used to evaluate energy saving measures for indoor swimming pools [22]. The results of the study have been compared with AHP and fuzzy AHP methods. In a study conducted in South India, a household energy efficiency survey was conducted in 125 houses and analyzed using the Best Worst Method (BWM) [25]. Various factors and sub-factors were listed as a result of the study. Finally, Ecer et al. [11] suggested that IMCSP can be used to improve energy efficiency in buildings under the assumption of certainly known parameters. Contribution of these papers are presented in Table 1 as follows along with the contributions of this study.

In real life problems, it may not always be possible to reach values based on measurement. At this point, the information obtained from the opinions of the experts of the problem becomes very important. In such cases, fuzzy logic is a valuable and important tool in the processing and use of this information. Therefore, this study is an extension of Ecer et al. [11]'s work with fuzzy parameters.

\section{Methods}

\subsection{Inverse multiple criteria sorting problem}

Decision making models were applied on many problems by researchers and a large number of studies were published on this subject. The main aim in a class of decision making applications is placement of alternatives into predefined groups. If there are more than one criterion to consider, these kinds of decisions can be handled by multiple criteria classification and sorting techniques. The difference between multiple criteria sorting and classification problems is based on the structure of classes. Multiple criteria classification problem refers existence of nominal groups, while ordered classes from the most preferred to the least preferred exists in multiple criteria sorting problem.

Multiple criteria sorting problem can be defined as follows:

$A=\left\{a_{1}, a_{2}, \ldots, a_{m}\right\}$ denotes the set of $m$ alternatives. Let's assume that these $m$ alternatives are evaluated in views of $n$ criteria denoted by the set $g=\left\{g_{1}, g_{2}, \ldots, g_{n}\right\}$ and the performance of alternative $i$ in views of criterion $j$ is expressed by $g_{j}\left(a_{i}\right)$. The decision maker wants to sort alternatives by assigning into $q$ classes. $C_{k}$ shows $k$ th class, where $C_{1}$ is the most desired and $C_{q}$ is the least desired class. Set of classes is denoted by $K=\{1,2, \ldots, q\}$. Assignment of alternatives into classes is the concern of multiple criteria sorting problem [17]. 
TABLE 1. Contribution of author(s).

\begin{tabular}{|c|c|c|c|}
\hline Author(s) & Problem & Method & Uncertainty \\
\hline Diakaki et al. [10] & $\begin{array}{l}\text { Building energy efficiency improve- } \\
\text { ment at design phase }\end{array}$ & $\begin{array}{l}\text { Multi-objective opti- } \\
\text { mization }\end{array}$ & No \\
\hline Wang et al. [28] & $\begin{array}{l}\text { Energy performance assessment for } \\
\text { existing buildings }\end{array}$ & $\begin{array}{l}\text { Review of measure- } \\
\text { ment and assessment } \\
\text { methods }\end{array}$ & No \\
\hline Kabak et al. [16] & $\begin{array}{l}\text { Energy performance assessment for } \\
\text { existing buildings }\end{array}$ & ANP & Fuzzy \\
\hline Hu et al. [13] & $\begin{array}{l}\text { Energy performance assessment for } \\
\text { existing buildings }\end{array}$ & ANP & Fuzzy \\
\hline $\mathrm{Xu}$ et al. [30] & $\begin{array}{l}\text { Building energy efficiency retrofit } \\
\text { for existing buildings }\end{array}$ & ANP & No \\
\hline Bayata and Temiz [4] & $\begin{array}{l}\text { Energy efficiency optimization in } \\
\text { building design }\end{array}$ & NSGA-II & No \\
\hline Delgarm et al. [8] & $\begin{array}{l}\text { Energy efficiency optimization in } \\
\text { building design }\end{array}$ & MOPSO & No \\
\hline Ignatius et al. $[14]$ & Green building assessment & ANP-QFD & Fuzzy \\
\hline Migilinskas et al. [20] & $\begin{array}{l}\text { Building energy performance evalu- } \\
\text { ation }\end{array}$ & ARAS & No \\
\hline Jeong et al. [15] & $\begin{array}{l}\text { Energy performance assessment for } \\
\text { existing buildings }\end{array}$ & Clustering analysis & No \\
\hline Bac et al. [2] & $\begin{array}{l}\text { Determination of the best HVAC } \\
\text { system alternative for a factory } \\
\text { building }\end{array}$ & SWARA-WASPAS & No \\
\hline Nikolic et al. [22] & $\begin{array}{l}\text { Energy auditing of indoor swim- } \\
\text { ming facilities }\end{array}$ & AHP, WSM & Fuzzy \\
\hline Qarnain et al. [25] & $\begin{array}{l}\text { Evaluation of energy efficiency fac- } \\
\text { tors in residential buildings }\end{array}$ & BWM & No \\
\hline Ecer et al. $[11]$ & $\begin{array}{l}\text { Energy efficiency improvement for } \\
\text { existing buildings }\end{array}$ & Goal programming & No \\
\hline This study & $\begin{array}{l}\text { Energy efficiency improvement for } \\
\text { existing buildings }\end{array}$ & Integer programming & Fuzzy \\
\hline
\end{tabular}

Multiple criteria classification and sorting problems have a wide range of application area, such as healthcare, pattern recognition, human resources management, financial management and economics [31].

IMCSM tries to determine the best actions from the possible actions set, which change alternative performance on some criteria, by this way, ensure the desired sorting of objects [21]. Under the assumption of each action affects at least one alternative in views of at least one criterion and has a cost associated with it, the goal of the problem will be determination of actions to ensure desired sorting at minimum total cost. Moreover, based on the sorting approach, view point of decision maker and problem specific restrictions different models can be developed for this problem.

The basic for IMCSM is given as follows:

$$
\min \sum_{k=1}^{m} c_{k} x_{k}
$$

subject to

$$
o_{i j}^{\prime}=o_{i j}+\sum_{k=1}^{m} \delta_{i j k} x_{k} \quad \forall i, j
$$




$$
\begin{array}{ll}
\sum_{j=1}^{n} w_{j} o_{i j}^{\prime} \geq b^{p_{i}} & \forall i \\
x_{k} \in\{0,1\} & \forall k .
\end{array}
$$

Objective function of the model is expressed by equation (3.1) and states that the total cost of selected actions should be minimized. Effect of selected actions over alternatives defined in equation (3.2). Alternatives are assigned into classes by using weighted sum function and final performances of alternatives. If the least desired class for alternative $i$ is defined as class $p$, then the weighted sum for this alternative must be greater than or equal to the lower bound of class $p$. This condition is expressed by equation (3.3). Equation (3.4) states that the decision variable $x$ is a binary variable, which shows the selection decision for action $k$.

There are quite little number of studies on IMCSP published in the current literature. The oldest one of these studies is Özpeynirci et al. [23], which is presented at the Operations Research and Industrial Engineering Congress in 2015 and can be considered as the first study in which the problem was presented. In this study, two mathematical models of the problem are proposed. The first model determines the improvement actions to be selected at the lowest cost and the second one finds the best sorting under the budget constraint. Later, experimental study results of these models have been presented as an article for both cases of existence of deterministic parameters and robust solutions for feasible values of the parameters [21]. Özpeynirci et al. [24] developed an interactive algorithm to solve IMCSP for a case study concerning on classification improvement of public buses. In a recent study on IMSCP [29], reducing the vital effects of nuclear power plants is model as an IMSCP. In the study, models are introduced that determine the central smallest actions, aim to obtain robust results for the worst case in order to learn the examples of the parameters, and reduce the expected effect level in the probabilistic case. Studies related to building energy performance optimization were generally focused on optimization of design parameters for buildings at design stage. Ecer et al. [11] suggested that IMCSP can be used to improve energy efficiency in buildings under the assumption of certainly known parameters.

\subsection{Solution approach for mathematical models with fuzzy parameters}

In some cases, all parameters of a linear programming problem may be defined by fuzzy uncertainty. This type of problems is formulated as follows:

$$
\begin{aligned}
\max & z=f(c, x)=\tilde{c} x \\
& g_{i}(x)=(\tilde{A} x)_{i} \leq \tilde{b}_{i} \quad i=1,2, \ldots, m \\
& x \geq 0
\end{aligned}
$$

Carlsson and Korhonen [6] proposed a trade-off approach for given fuzzy linear programming problem. Before the solution of the fuzzy problem, the increasing form of parameter ranges $(c, A, b)$ needed for the solution of the certain form of the problem. To do so, parameter ranges $\left[c_{0}, c_{1}\right),\left[A_{0}, A_{1}\right)$ and $\left[b_{0}, b_{1}\right)$ for the possible values of problem parameters are defined. The lower bounds of these intervals show the values that obtaining the solution is more certain and they are risk-free values. On the other hand, upper bounds show unrealistic and impossible parameter values. The solution obtained by using these values are unreal. Changing parameter values from risk-free values to impossible ones means a movement from reliable solutions optimistic solutions. After this movement, solutions with higher satisfaction degree are preferred to solutions with lower satisfaction degree. Optimal parameters can be determined by using defined preference based functions of each interval.

Carlsson and Korhonen considered the relationship between any solution of the problem and parameters of the problem. The solution of the model $\left(z^{*}=z^{*}(c, A, b)\right)$ is an increasing function of $c, A$ and $b$. With this aim, membership functions of $c, A$ and $b$ can be considered to be monotone decreasing functions. Membership functions of monotone decreasing functions can be linear, piecewise linear, hyperbolic, exponential, etc. functions. 
By considering the trade-off approach and under $\mu \in[0,1]$ condition, $g_{c}, G_{A}$ and $g_{b}$ are inverse functions of $\mu_{c}, \mu_{A}$ ve $\mu_{b}$, respectively and the following transitions are valid.

$$
c=g_{c}(\mu), \quad A=G_{A}(\mu) \text { and } \quad b=g_{b}(\mu) .
$$

By using these equations in the model, the problem can be written as follows:

$$
\begin{aligned}
\max & z=f(c, x)=g_{c}(\mu) x \\
& {\left[G_{A}(\mu)\right] x \leq g_{b}(\mu) } \\
& x \geq 0 .
\end{aligned}
$$

If $\mu$ values are assumed to be decision variable, this model becomes a nonlinear programming model. If $\mu$ values are given or can be predefined, this model can be solved by using a linear programming solution technique and solution values correspond to the $\mu$ value can be obtained. A solution corresponds to any $\mu$ value can be expressed as a point $\left(z^{*}, \mu\right)$ in two dimensional space. Decision maker can choose the suitable solution among these points. The solution process of linear programming models with Carlsson and Korhonen's approach can be defined as:

Step 1. Start from $\mu=0$ point and assume that you are trying to obtain $s$ solutions. So, at each solution step $\mu$ will be increased by $Q=1 / s$.

Step 2. Solve the linear programming model for $\mu=0$ and find the optimal solution.

Step 3. Insert the $\left(\mu, z^{*}\right)=\left(0.0, z_{\mu=0.0}^{*}\right)$ value into solution table. Then, take $\mu=\mu+Q$. If $\mu>1$, go to Step 4. Otherwise, go to Step 2 and solve the model for $\mu=\mu+Q$.

Step 4. The solution table represents the relation between membership value and optimal solution of the model. By analyzing this relation, decision maker can find the optimal solution for acceptable uncertainty level of himself/herself.

\section{Problem DESCRIPTION}

In this study, a mathematical model for determination of improvement strategies of multiple criteria sorting application is proposed. To improve the sorting results, some of the predetermined actions will be applied. Each action causes a cost associated with it and needs some time to be completed. Actions can be performed by different companies. Each company can perform one action and different companies can perform different actions at the same time. Each action can be only performed by one company. Objects are measured in views of several criteria and lower value of each criterion shows better performance of the object. Weighted sum of object performance on each criterion is calculated and resulting value is the determinant of object class. Also, within the proposed model, uncertainty of some parameters is taken into account. It is assumed that there is no sufficient amount of data for uncertain parameters, so the parameter values are determined based on opinions of experienced people and defined as fuzzy elements. Based on the aforementioned assumptions of the problem, the formulation of the mathematical model of the problem with fuzzy parameters is presented as follows:

\section{Indices}

$i: \quad$ objects

$j: \quad$ criteria

$k$ : actions

$l$ : companies

$h$ : classes

\section{Parameters}

$\tilde{c}_{k l}$ : $\quad$ fuzzy value of performing cost of action $k$ by company $l$

$\tilde{t}_{k l}$ : fuzzy completion time for action $k$ offered by company $l$ 
$\tilde{B}: \quad$ fuzzy budget limit

$o_{i j}^{\prime}$ : final performance score of object $i$ in views of criterion $j$

$o_{i j}$ : initial performance score of object $i$ in views of criterion $j$

$\tilde{\delta}_{i j k}$ : effect of action $k$ on object $i$ in views of criterion $j$

$w_{j}$ : weight of criterion $j$

$b^{h}$ : $\quad$ upper level of aggregated performance score to be assigned to class $h$

$M: \quad$ a sufficiently big number

Decision variables

$\mathrm{CTG}_{l}$ : total completion time for company $l$

CT: $\quad$ completion time for all companies

$$
\begin{aligned}
& x_{k l}= \begin{cases}1, & \text { if company } l \text { is selected to perform action } k \\
0, & \text { otherwise }\end{cases} \\
& y_{h i}= \begin{cases}1, & \text { if object } i \text { is assigned to class } h \\
0, & \text { otherwise }\end{cases}
\end{aligned}
$$

Mathematical model

$$
Z_{\max }=\sum_{h=1}^{h_{\min }} \sum_{i=1}^{m} y_{h i}
$$

subject to

$$
\begin{array}{ll}
\sum_{k=1}^{K} \sum_{l=1}^{L} \tilde{c}_{k l} x_{k l} \leq \tilde{B} & \\
o_{i j}^{\prime}=o_{i j}+\sum_{k=1}^{K} \tilde{\delta}_{i j k} \sum_{l=1}^{L} x_{k l}, & \forall i, j \\
\sum_{j=1}^{n} o_{i j}^{\prime} w_{j} \geq b^{h-1}-M\left(1-y_{h i}\right), & \forall i, \quad \forall h=2, \ldots, t \\
\sum_{j=1}^{n} o_{i j}^{\prime} w_{j} \leq b^{h}+M\left(1-y_{h i}\right), & \\
\sum_{l=1}^{L} x_{k l} \leq 1, & \forall i, \quad \forall h=1, \ldots, t-1 \\
\sum_{h=1}^{t} y_{h i}=1, & \forall k \\
\sum_{k=1}^{K} \widetilde{t}_{k l} x_{k l} \leq \mathrm{CTG} \mathrm{C}_{l} & \\
\mathrm{CT} \geq \mathrm{CTG}, & \\
\mathrm{CT} \leq \tilde{T} & \\
x_{k l} \in\{0,1\}, & \forall l \\
y_{h i} \in\{0,1\}, & \forall k, l \\
\mathrm{CTG} & \\
\mathrm{CT} \geq 0 \text { and integer. } &
\end{array}
$$




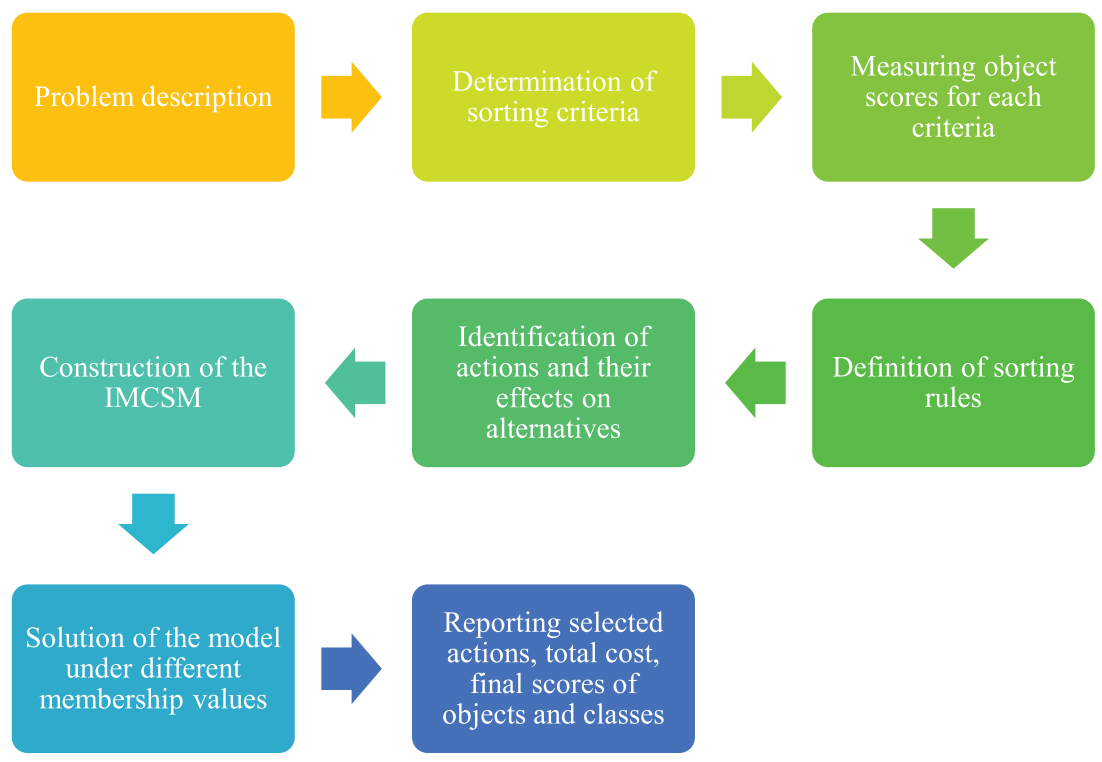

FiguRE 1. Flowchart of the proposed approach.

The objective function of the model is presented in equation (4.1). The goal of the model is to maximize number of alternatives assigned to desired classes. Equation (4.2) shows the budget limitation. Final performance scores are calculated by using equation (4.3). Assignment of alternatives to classes are done according to the procedure described in equations (4.4) and (4.5). Equation (4.6) states that each action can be performed by at most one company. Each alternative must be assigned to a class. This requirement is expressed in equation (4.7). Completion time of work is calculated by equations (4.8)-(4.10). Decisions for selection of actions and assignment of alternatives are binary variables and defined in equations (4.11) and (4.12). Equations (4.13) and (4.14) express that the completion times for company and total work are positive integer variables.

The main aim of this study is to propose a mathematical formulation and a solution approach to improve obtained results in multiple criteria sorting applications with fuzzy parameters. To do so, IMSCP is reformulated with fuzzy parameters and Carlsson and Korhonen's fuzzy solution approach is employed to obtain solution under different membership values. Decision makers may choose one of the solutions according to their acceptable uncertainty level. The solution procedure with the proposed model is given in Figure 1 as follows.

The first step of the proposed approach is problem description. Decision makers have to define their goal(s), limitations and restrictions with problem assumptions and alternatives to be sorted. Then, criteria to be used for sorting alternatives must be determined. Criteria should be selected among effective factors on sorting of alternatives and their definitions must be clear. After criteria definitions, performance score of each alternative for each criterion have to be measured. Next, sorting rules for the application must be defined. Definition of sorting rule means the aggregation function for performance scores and assignment conditions for each class. When sorting rules are defined, the initial conditions for alternatives can be determined.

The next step of the application is identification of actions and their effects. Possible actions are identified in this step with their cost, time, etc. parameters and their effects on alternatives. At that point all, parameters for construction of sorting model are collected. IMCSP is constructed at this point with collected information about the problem and possible parameter values. Proposed IMCSP model with fuzzy parameters is solved under different membership values according to the methodology of Carlsson and Korhonen. At the last step, objective function value, budget consumption amounts and selected actions are presented in the solution table 
for the decision maker. According to the acceptable uncertainty of decision maker, final performance scores of alternatives and their classes are presented.

\section{AN APPLICATION OF BUILDING ENERGY EFFICIENCY IMPROVEMENT}

Energy efficiency is a vital issue in terms of natural resources and the environment. A regulation on taxation of buildings based on energy efficiency is being planned in Turkey. On the current basis, energy efficiency is expressed by building energy labels, from A (the most efficient) to $G$ (the least efficient). Buildings are labeled based on the energy consumption and different attributes of buildings are taken into account. So, the labeling process can be considered as a multi-criteria sorting problem. In this study, energy labeling of buildings is modeled as an inverse multi-criteria sorting problem with fuzzy parameters in order to determine the actions, which are taken to improve the energy labels and decrease tax expenses of buildings by reducing the harmful effects of buildings on the environment.

Energy Identification Certificate is a document that includes the information of energy requirements and energy consumption classification of building, in order to provide efficient and effectively use of energy and energy resources in buildings. Determining the energy classes of buildings is obligatory in Turkey as in many countries. This obligation has been registered with the Energy Efficiency Law No. 5627 enacted in 2007 and the Regulation on Energy Performance in Buildings related to this law.

Building Energy Performance (BEP) must be calculated to form the Energy Identification Certificate. Annual energy needs and $\mathrm{CO}_{2}$ emission related to the energy needs are defined for calculation of Building Energy Performance. After this calculation, building is assigned to one of the energy classes from the best (A) to the worst $(\mathrm{G})$ based on the reference building. Design of new buildings are requested to meet at least $\mathrm{C}$ class of energy efficiency and it is being planned to apply an incentive tax reduction policy based on energy classes of buildings in the future.

\subsection{Problem data}

In this part, application of the proposed model is presented for building energy efficiency improvement planning for a site management in Ankara, Turkey. According to the Regulation on Energy Performance in Buildings, the energy label of new buildings has to be at least C. Site management wants as much number as buildings among the 10 buildings in their site to have acceptable labels for the regulation. But they have a budget limitation of $210000 \mathrm{TL}$ and improvement actions have to be completed in 15 days. Moreover, the budget can be increased up to $60000 \mathrm{TL}$ for much improvement and time limit can be increased by 5 more days. So, the objective function is maximization of number of buildings in desired classes (A, B, and C) subject to budget and time restrictions. Improvement actions can be performed by different companies, which provide different cost and completion time offers for improvement actions. Each group can perform one action at one time, but the groups can work together. Moreover, an improvement action can be performed by only one company.

Sorting criteria for buildings are defined as the same criteria in the study of Kabak et al. [16] since it proposes an evaluation model for buildings in Turkey and criteria in this study are determined based on the same regulations. These criteria are Location and climate data (C1), Geometrical shape (C2), Building envelope (C3), Mechanical Systems (C4), Lighting system (C5), Hot water system (C6), and Renewable energy and Cogeneration $(\mathrm{C} 7)$.

Then, the performance scores of buildings are measured for these criteria and presented in Table 2 . The scores of buildings are normalized into 0-30 interval, where 0 shows the best performance and 30 shows the worst. Parameter values are determined based on the opinions of a 20-year experienced professional on a reputable building construction company in Ankara.

Sorting of buildings are made by using weighted sum function. To do so, weight values of criteria are taken the values in Kabak et al. [16]. By using weighted sum an aggregated Building Energy Score (BES) value is obtained and this value is used for assignment of building into a predefined class. Upper bound of BES value for each energy label is given in Table 3 as follows. 
TABLE 2. Initial performance score of buildings in views of criteria.

\begin{tabular}{llllllll}
\hline \hline Building & C1 & C2 & C3 & C4 & C5 & C6 & C7 \\
\hline B1 & 11 & 16 & 15 & 11 & 7 & 9 & 3 \\
B2 & 25 & 25 & 21 & 23 & 24 & 22 & 27 \\
B3 & 12 & 1 & 3 & 1 & 2 & 2 & 2 \\
B4 & 13 & 19 & 16 & 9 & 8 & 18 & 15 \\
B5 & 20 & 26 & 28 & 8 & 7 & 13 & 12 \\
B6 & 17 & 12 & 14 & 11 & 9 & 16 & 13 \\
B7 & 11 & 19 & 11 & 16 & 5 & 20 & 17 \\
B8 & 19 & 20 & 23 & 23 & 16 & 24 & 26 \\
B9 & 21 & 15 & 23 & 20 & 19 & 15 & 18 \\
B10 & 18 & 13 & 22 & 10 & 10 & 15 & 15 \\
\hline
\end{tabular}

TABLE 3. Intervals of BES value for each energy label.

\begin{tabular}{llllllll}
\hline \hline Energy label & A & B & C & D & E & F & G \\
\hline Upper bound for BES Value & 5 & 10 & 14 & 18 & 22 & 26 & 30 \\
\hline
\end{tabular}

TABLE 4. Initial energy labels of buildings.

\begin{tabular}{lllllllllll}
\hline \hline Building & B1 & B2 & B3 & B4 & B5 & B6 & B7 & B8 & B9 & B10 \\
\hline Energy label & B & F & A & C & D & C & C & E & E & D \\
\hline
\end{tabular}

Criteria weights are assumed to be $0.27,0.07,0.10,0.16,0.12,0.08$ and 0.20 , respectively. After these definitions, energy labels for each building are obtained by using the sorting rules. Initial energy labels for buildings are presented in Table 4.

According to Table 3, five buildings (B2, B5, B8, B9, B10) have unacceptable energy labels. Thus, improvement actions have to be analyzed.

Next, possible improvement actions are collected from 3 companies with their effect on buildings, costs and completion times. Possible improvement actions are chosen as five possible actions and these actions are determined as changing roof of all buildings (A1), changing HVAC system of buildings (A2), changing the lighting systems (A3), building a central hot water system (A4) and installing solar panels on roofs to support energy demand (A5). Effects of actions are uncertain and given with possible values in Table 5. Moreover, as it seen in Table 6, proposals of companies include different cost and completion time values from one company to another. Site management has to form the improvement plan by considering uncertainty and variability of offers from 3 companies.

After determination of problem parameters, IMCSM with fuzzy parameters is constructed. The goal of this model is to maximize the numbers of buildings assigned into desired classes. Performance scores of buildings are aggregated by using weighted sum function and calculated BES value is used for determination of building label. There are different companies for each improvement action with different costs and completion times. Moreover, some problem parameters (action costs, budget limit, effects of actions, completion times and time limit) are fuzzy uncertain. Different companies can perform their activities together, but each company can perform one job at a time. 
TABLE 5. Offers for improvement actions.

\begin{tabular}{llllllll}
\hline \hline Action & \multicolumn{2}{c}{ A1 } & \multicolumn{2}{c}{ A2 } & A3 & A4 & A5 \\
\hline Effects on & C2 & C3 & C4 & C6 & C5 & C6 & C7 \\
\hline B1 & {$[-7,-9)$} & {$[-8,-9)$} & {$[-9,-10)$} & {$[-7,-8)$} & {$[-5,-7)$} & {$[-6,-8)$} & {$[0,-1)$} \\
B2 & {$[-14,-18)$} & {$[-13,-16)$} & {$[-18,-19)$} & {$[-14,-17)$} & {$[-13,-16)$} & {$[-12,-15)$} & {$[-21,-25)$} \\
B3 & {$[-2,0)$} & {$[0,-2)$} & {$[0,0)$} & {$[0,-1)$} & {$[0,-1)$} & {$[0,0)$} & {$[0,-1)$} \\
B4 & {$[-10,-11)$} & {$[-8,-12)$} & {$[-6,-7)$} & {$[-14,-15)$} & {$[-6,-7)$} & {$[-11,-12)$} & {$[-8,-10)$} \\
B5 & {$[-16,-19)$} & {$[-13,-14)$} & {$[-5,-6)$} & {$[-6,-9)$} & {$[-3,-4)$} & {$[-8,-9)$} & {$[-6,-7)$} \\
B6 & {$[-6,-8)$} & {$[-9,-10)$} & {$[-8,-9)$} & {$[-12,-14)$} & {$[-4,-5)$} & {$[-8,-10)$} & {$[-7,-8)$} \\
B7 & {$[-10,-12)$} & {$[-4,-6)$} & {$[-10,-12)$} & {$[-14,-15)$} & {$[-1,-2)$} & {$[-13,-14)$} & {$[-12,-13)$} \\
B8 & {$[-12,-15)$} & {$[-14,-18)$} & {$[-16,-18)$} & {$[-15,-16)$} & {$[-9,-10)$} & {$[-16,-18)$} & {$[-20,-22)$} \\
B9 & {$[-5,-7)$} & {$[-15,-16)$} & {$[-14,-15)$} & {$[-10,-13)$} & {$[-13,-16)$} & {$[-6,-7)$} & {$[-7,-9)$} \\
B10 & {$[-8,-9)$} & {$[-15,-17)$} & {$[-5,-7)$} & {$[-11,-12)$} & {$[-6,-8)$} & {$[-6,-9)$} & {$[-11,-13)$} \\
\hline
\end{tabular}

TABLE 6. Cost and completion time offers of companies.

\begin{tabular}{lllllll}
\hline \hline Action & Company & A1 & A2 & A3 & A4 & A5 \\
\hline \multirow{2}{*}{ cost $(\times 1000$ TL) } & L1 & {$[150,110)$} & {$[190,170)$} & {$[40,30)$} & {$[90,70)$} & {$[100,90)$} \\
& L2 & {$[140,120)$} & {$[140,135)$} & {$[50,35)$} & {$[80,70)$} & {$[120,80)$} \\
& L3 & {$[150,100)$} & {$[175,160)$} & {$[45,35)$} & {$[90,80)$} & {$[115,90)$} \\
\hline Time (days) & L1 & {$[15,12)$} & {$[10,7)$} & {$[10,9)$} & {$[11,8)$} & {$[8,6)$} \\
& L2 & {$[18,14)$} & {$[15,14)$} & {$[10,8)$} & {$[10,8)$} & {$[9,6)$} \\
& L3 & {$[16,13)$} & {$[9,7)$} & {$[11,9)$} & {$[10,7)$} & {$[10,6)$} \\
\hline
\end{tabular}

TABLE 7. Solution results for different membership values.

\begin{tabular}{lllll}
\hline \hline Membership value & Objective value & Selected actions & Budget consumed & Completion time \\
\hline Initial state & 5 & - & 0 & - \\
1.0 & 7 & A1 (L1) & 150000 & 15 \\
0.9 & 7 & A1 (L1) & 146000 & 15 \\
0.8 & 7 & A3 (L2), A5 (L1) & 145000 & 10 \\
0.7 & 7 & A4 (L3), A5 (L2) & 195000 & 10 \\
0.6 & 8 & A2 (L2), A5 (L1) & 234000 & 15 \\
0.5 & 8 & A2 (L2), A5 (L1) & 232500 & 15 \\
0.4 & 8 & A2 (L2), A5 (L1) & 231000 & 15 \\
0.3 & 8 & A2 (L2), A5 (L1) & 229500 & 15 \\
0.2 & 8 & A2 (L3), A5 (L2) & 251000 & 8 \\
0.1 & 10 & A2 (L2), A3 (L3), A5 (L1) & 262500 & 15 \\
0.0 & 10 & A2 (L2), A3 (L3), A5 (L1) & 260000 & 14 \\
\hline
\end{tabular}

\subsection{Solution results}

Proposed IMCSP with fuzzy parameter is solved under different membership values according to the methodology of Fuzzy Parametric Solution Approach [31] on a PC with Intel@ Core ${ }^{\mathrm{TM}}$ i7-5500U @2.40 GHz processor and 8GB RAM with CPLEX solver of GAMS 24.1.3 optimization software. Objective function value, budget consumed and selected actions are presented in Table 7 as the solution table for the decision maker.

According to the acceptable uncertainty of decision maker, one of these solutions can be selected as an improvement plan. Let's assume that the acceptable uncertainty level for decision maker is 0.4, which means a 
TABLE 8. Final performance scores and classes of alternatives for $\mu=0.6$.

\begin{tabular}{lllllllll}
\hline \hline Alternative & $\mathrm{C} 1$ & $\mathrm{C} 2$ & $\mathrm{C} 3$ & $\mathrm{C} 4$ & $\mathrm{C} 5$ & $\mathrm{C} 6$ & $\mathrm{C} 7$ & Class \\
\hline B1 & 11 & 16 & 15 & 1.6 & 7 & 1.6 & 2.6 & $\mathrm{~B}$ \\
B2 & 25 & 25 & 21 & 4.6 & 24 & 6.8 & 4.4 & $\mathrm{D}$ \\
B3 & 12 & 1 & 3 & 1 & 2 & 1.6 & 1.6 & $\mathrm{~A}$ \\
B4 & 13 & 19 & 16 & 2.6 & 8 & 3.6 & 6.2 & $\mathrm{~B}$ \\
B5 & 20 & 26 & 28 & 2.6 & 7 & 5.8 & 5.6 & $\mathrm{C}$ \\
B6 & 17 & 12 & 14 & 2.6 & 9 & 3.2 & 5.6 & $\mathrm{~B}$ \\
B7 & 11 & 19 & 11 & 5.2 & 5 & 5.6 & 4.6 & $\mathrm{~B}$ \\
B8 & 19 & 20 & 23 & 6.2 & 16 & 8.6 & 5.2 & $\mathrm{C}$ \\
B9 & 21 & 15 & 23 & 5.6 & 19 & 3.8 & 10.2 & $\mathrm{D}$ \\
B10 & 18 & 13 & 22 & 4.2 & 10 & 3.6 & 3.2 & $\mathrm{C}$ \\
\hline
\end{tabular}

solution with 0.6 membership value is acceptable. For this solution final performance scores of alternatives and their classes are presented in Table 8.

As it can be seen from Tables 7 and 8, due to the selection of A2 and A5 as actions to be performed, performance scores of buildings were changed in views of $\mathrm{C} 4, \mathrm{C} 6$, and $\mathrm{C} 7$. Under this uncertainty level, completion time will be 15 days and 234000 TL of budget will be consumed. After these changes, 8 of 10 buildings are assigned to desired classes. Different improvement plans can be developed to assign the other buildings.

\section{Managerial insights}

The main aim of this study is to propose a mathematical model with fuzzy parameters and a solution approach for it to support improvement planning decisions in classification based decision problems under uncertainty. By using the proposed model, decision and policy makers may obtain optimal improvement plans under fuzzy uncertainty. In some cases, values of problem parameters cannot be known exactly or no statistical data for these values can be obtained. Based on the opinions of experienced people in the application area, fuzzy values for parameters can be derived. This is the main reason for proposing a model with fuzzy parameters.

Solutions obtained from this model can lead policy makers to understand in which way they should make new regulations for continuous improvement. In some countries like Germany and England, an information package including energy efficiency improvement information is presented to real estate investors. This model can be considered as a development way for the current BEP-TR model in Turkey with an extension of energy efficiency improvement strategy suggestions. This model can also be used in energy efficiency topic by house owners and construction companies to develop optimal plans under uncertainty of parameters.

In most of the construction projects like the case study in this study, parameter values contain uncertainty. Each project may have specific characteristics, so parameters for its elements like completion times, costs, etc. may differ from any other project. To estimate the parameter values, asking opinions of some construction experts may be a useful approach. Moreover, other similar problems like class success improvement in education or hospital service quality improvement in healthcare systems can also be solved by using the proposed model. In such systems where collecting statistical data is difficult and historical data is insufficient, fuzzy logic is a useful tool for defining uncertain problem data. Fuzzy logic helps to express the evaluations made by experts on the value of a parameter based on their experience.

\section{Conclusion}

Energy efficiency is a very popular topic in today's world. Increasing population and developing technology leads more and more energy consumption by time. So, efficient use of energy is a key issue for a sustainable world. 
Energy efficiency of buildings is an important issue, due to the high proportion of energy consumption. Like many other countries, Turkey has made some regulations for energy efficiency evaluation and improvement in buildings and activities on this topic are also going on. The current energy labeling algorithm in Turkey (BEPTR) is just interested in measuring the energy needs. However, there are some algorithms around the world, which suggest improvement strategies besides presenting the energy label.

In this study, a decision model based on Inverse Multiple Criteria Sorting Problem with fuzzy parameters is proposed to determine energy efficiency improvement strategies for buildings. The proposed model is important in that it is the first study to apply IMCSP with fuzzy parameters. This model can be used as a decision support tool for property owners for selection of actions in order to improve energy efficiency of their properties. Also, construction companies working on energy efficiency improvement actions can use this model to support their improvement plan offers they prepare for their customers.

Also, this model can be considered as a generic model for improvement of multiple criteria sorting applications. Decision makers in different sectors like education, healthcare, production, etc., who is not happy or want to improve the class of objects in their application and don't have sufficient amount of data for problem parameters, can use this model to determine improvement strategies for their systems.

The main limitation of the study is presenting the solution of the model with an application of small dimension data. In further studies, solution capability of the proposed approach can be tested. Also, a decision support system with a user interface could be developed to present a useful tool for a wide range area of applications.

As an extension of the application, results of energy efficiency measurement algorithms in different countries can be compared with the results of the proposed approach. The proposed approach can also be utilized on different sorting problems such as education, healthcare, human resources management, etc. to improve present classes of objects. For example, Bhuniya et al. [5]'s study can be extended as a customer service level improvement study in a supply chain or Aktas et al. [1]'s study as a hospital service quality improvement study by using the proposed model. Also, the proposed model can be tested on several industrial case studies in further studies. In these case studies, effects of parameter value changes can be investigated by conducting sensitivity analyses.

\section{REFERENCES}

[1] A. Aktas, S. Cebi and I. Temiz, A new evaluation model for service quality of health care systems based on AHP and information axiom. J. Intell. Fuzzy Syst. 28 (2015) 1009-1021.

[2] U. Bac, K.A.M.S. Alaloosi and C. Turhan, A comprehensive evaluation of the most suitable HVAC system for an industrial building by using a hybrid building energy simulation and multi criteria decision making framework. J. Build. Eng. 37 (2021) 102153.

[3] R. Baki, An integrated, multi-criteria approach based on environmental, economic, social, and competency criteria for supplier selection. RAIRO-Oper. Res. 55 (2021) 1487-1500.

[4] O. Bayata and I. Temiz, Developing a model and software for energy efficiency optimization in the building design process: a case study in Turkey. Turkish J. Electr. Eng. Comput. Sci. 25 (2017) 4172-4186.

[5] S. Bhuniya, S. Pareek and B. Sarkar, A supply chain model with service level constraints and strategies under uncertainty. Alexandria Eng. J. 60 (2021) 6035-6052.

[6] C. Carlsson and P. Korhonen, A parametric approach to fuzzy linear programming. Fuzzy Sets Syst. 20 (1986) 17-30.

[7] A. Chakraborty, S. Maity, S. Jain, S.P. Mondal and S. Alam, Hexagonal fuzzy number and its distinctive representation, ranking, defuzzification technique and application in production inventory management problem. Granular Comput. 6 (2021) $507-521$.

[8] N. Delgarm, B. Sajadi, F. Kowsary and S. Delgarm, Multi-objective optimization of the building energy performance: a simulation-based approach by means of particle swarm optimization (PSO). Appl. Energy 170 (2016) 293-303.

[9] A. Dhara, G. Kaur, P.M. Kishan, A. Majumder and R. Yadav, An efficient decision support system for selecting very light business jet using CRITIC-TOPSIS method. Aircr. Eng. Aerosp. Technol. 94 (2022) 458-472.

[10] C. Diakaki, E. Grigoroudis, N. Kabelis, D. Kolokotsa, K. Kalaitzakis and G. Stavrakakis, A multi-objective decision model for the improvement of energy efficiency in buildings. Energy 35 (2010) 5483-5496.

[11] B. Ecer, M. Kabak and M. Dağdeviren, Goal programming model for bi-objective inverse multiple criteria sorting problem. J. Faculty Eng. Archit. Gazi Univ. 35 (2020) 1729-1736.

[12] M. Ghram and H.M. Frikhahela, ARAS-H: a ranking-based decision aiding method for hierarchically structured criteria. RAIRO-Oper. Res. 55 (2021) 2035-2054.

[13] S. Hu, F. Liu, C. Tang, X. Wang and H. Zhou, Assessing Chinese campus building energy performance using fuzzy analytic network approach. J. Intell. Fuzzy Syst. 29 (2015) 2629-2638. 
[14] J. Ignatius, A. Rahman, M. Yazdani, J. Šaparauskas and S.H. Haron, An integrated fuzzy ANP-QFD approach for green building assessment. J. Civil Eng. Manage. 22 (2016) 551-563.

[15] J. Jeong, T. Hong, C. Ji, J. Kim, M. Lee, K. Jeong and C. Koo, Improvements of the operational rating system for existing residential buildings. Appl. Energy 193 (2017) 112-124.

[16] M. Kabak, E. Köse, O. Kırılmaz and S. Burmaoğlu, A fuzzy multi-criteria decision making approach to assess building energy performance. Energy Build. 72 (2014) 382-389.

[17] O. Karsu, Approaches for inequity-averse sorting. Comput. Oper. Res. 66 (2016) 67-80.

[18] G. Kaur, R. Yadav and A. Majumder, An efficient intuitionistic fuzzy approach for location selection to install the most suitable energy power plant. In: 2nd International Conference on Recent Advances in Fundamental and Applied Sciences RAFAS, Punjab (2019).

[19] A.K. Manna, T. Benerjee, S.P. Mondal, A.A. Shaikh and A.K. Bhunia, Two-plant production model with customers' demand dependent on warranty period of the product and carbon emission level of the manufacturer via different meta-heuristic algorithms. Neural Comput. App. 33 (2021) 14263-14281.

[20] D. Migilinskas, E. Balionis, R. Dziugaite-Tumeniene and G. Siupsinskas, An advanced multi-criteria evaluation model of the rational building energy performance. J. Civil Eng. Manage. 22 (2016) 844-851.

[21] V. Mousseau, Ö. Özpeynirci and S. Özpeynirci, Inverse multiple criteria sorting problem. Ann. Oper. Res. 267 (2018) 379-412.

[22] J. Nikolic, D. Gordic, N. Jurisevic and D. Milovanovic, Energy auditing of indoor swimming facility with multi-criteria decision analysis for ranking the proposed energy savings measures. Energ. Effic. 14 (2021) 36.

[23] Ö. Özpeynirci, V. Mousseau and S. Özpeynirci, Ters Çok AmaçlıSınıflandırma Problemleri. Yöneylem Araştırması/Endüstri Mühendisliği 35. Ulusal Kongresi, Ankara (2015).

[24] Ö. Özpeynirci, S. Özpeynirci and V. Mousseau, An interactive approach for inverse multiple criteria sorting problem. J. Multi-Criteria Decis. Anal. 28 (2021) 160-169.

[25] S. Qarnain, S. Muthuvel and S. Bathrinath, Modelling of driving factors for energy efficiency in buildings using Best Worst Method. Mater. Today Proc. 39 (2021) 137-141.

[26] M. Rahaman, S.P. Mondal, A.A. Shaikh, P. Pramanik, S. Roy, M.K. Maiti, R. Mondal and D. De, Artificial bee colony optimization-inspired synergetic study of fractional-order economic production quantity model. Soft Comput. 24 (2020) 1534115359.

[27] M. Rahaman, S.P. Mondal, S. Alam and A. Goswami, Synergetic study of inventory management problem in uncertain environment based on memory and learning effects. Sädhanā 46 (2021) 39.

[28] S. Wang, C. Yan and F. Xiao, Quantitative energy performance assessment methods for existing buildings, Energy Build. 55 (2012) 873-888.

[29] T.R. Wang, N. Pedroni, E. Zio and V. Mousseau, Identification of protective actions to reduce the vulnerability of safety-critical systems to malevolent intentional acts: an optimization-based decision-making approach. Risk Anal. 40 (2020) 565-587.

[30] P. Xu, E.H.W. Chan, H.J. Visscher, X. Zhang and Z. Wu, Sustainable building energy efficiency retrofit for hotel buildings using EPC mechanism in China: analytic Network Process (ANP) approach. J. Cleaner Prod. 107 (2015) 378-388.

[31] C. Zopounidis and M. Doumpos, Multi criteria classification and sorting methods: a literature review. Eur. J. Oper. Res. 138 (2002) 229-246.

\section{Subscribe to Open (S2O)}

\section{A fair and sustainable open access model}

This journal is currently published in open access under a Subscribe-to-Open model (S2O). S2O is a transformative model that aims to move subscription journals to open access. Open access is the free, immediate, online availability of research articles combined with the rights to use these articles fully in the digital environment. We are thankful to our subscribers and sponsors for making it possible to publish this journal in open access, free of charge for authors.

\section{Please help to maintain this journal in open access!}

Check that your library subscribes to the journal, or make a personal donation to the $\mathrm{S} 2 \mathrm{O}$ programme, by contacting subscribers@edpsciences.org

More information, including a list of sponsors and a financial transparency report, available at: https://www. edpsciences.org/en/maths-s2o-programme 